\title{
Bone resorbing activity of surface-associated material from Actinobacillus actinomycetemcomitans and Eikenella corrodens
}

\author{
S. MEGHJI, M. WILSON*, P. BARBER $\dagger$ and B. HENDERSON
}

Maxillofacial Surgery Research Unit, " Department of Microbiology and $\dagger$ Electron Microscopy Unit, Eastman Dental Institute, University of London, 256 Gray's Inn Road, London WC1X 8LD

\begin{abstract}
Summary. The results of this study demonstrate that saline extracted surface-associated material (SAM) of Actinobacillus actinomycetemcomitans and Eikenella corrodens stimulates bone resorption at picomolar concentrations. Various inhibitors of known osteolytic mediators-indomethacin, interleukin-1 receptor antagonist (IL-1ra) and a neutralising antibody to murine tumour necrosis factor (TNF) $\alpha$ - were tested to determine the mechanism of action of these SAMs. Bone resorption induced by SAM from E. corrodens was slightly inhibited by indomethacin and almost completely inhibited by blocking the action of TNF $\alpha$; that from A. actinomycetemcomitans was not significantly affected by either of these inhibitors.
\end{abstract}

\section{Introduction}

Periodontal disease (PD) is the commonest chronic inflammatory disease afflicting man, and the destruction of alveolar bone is the most severe consequence of this disease. Although the stimulus that promotes bone breakdown in PD is still unresolved, it is likely that bacterial components which can penetrate into the periodontal tissues are involved. Bacterial lipopolysaccharide (LPS) appears to be of prime importance ${ }^{1}$ but surface-associated material (SAM) from Actinobacillus actinomycetemcomitans which does not contain LPS is a more potent stimulator of bone resorption in vitro and significantly more active, on a dry weight basis, than LPS from the same organism. ${ }^{2}$ The ready solubility of this SAM coupled with its potent osteolytic activity supports the view that it may be a major factor in bone resorption in $\mathrm{PD} .{ }^{2} \mathrm{In}$ this study, the capacity of SAM from A. actinomycetemcomitans and Eikenella corrodens to induce bone resorption in vitro have been compared by the murine calvarial bone resorption assay. The mechanism by which the SAM produces bone breakdown has been investigated with various inhibitors and antagonists of the major osteolytic mediators believed to be active in pathological bone remodelling.

\section{Materials and methods}

\section{Extraction of bacterial SAM}

A. actinomycetemcomitans strain $\mathrm{Y} 4$ was grown at $37^{\circ} \mathrm{C}$ on Brain Heart Infusion Agar (Oxoid) under anaerobic conditions (Gas Pak System, Oxoid). E. corrodens NCTC 10596 was grown at $37^{\circ} \mathrm{C}$ under anaerobic conditions on a medium consisting of Brain Heart Infusion Agar (Oxoid) supplemented with (/L) cysteine- $\mathrm{HCl} 0.375 \mathrm{~g}$, haemin $0.25 \mathrm{~g}$ and menadione $0.05 \mathrm{~g}$ (all from BDH). Bacteria were grown on solid media in an effort to enhance production of extracellular polymers. After 3-4 days, all cultures were inspected visually for contamination, stained with Gram's stain, removed from the plates with sterile saline and then centrifuged at $30000 \mathrm{~g}$ for $30 \mathrm{~min}$ at $4^{\circ} \mathrm{C}$. The washing procedure was repeated, the cells were lyophilised and the SAM was extracted as described previously. ${ }^{2}$ Briefly, the cells were stirred gently in sterile saline at $4^{\circ} \mathrm{C}$ for $1 \mathrm{~h}$ and then sedimented by centrifugation. This process was repeated twice and the combined aqueous phases were pooled. The SAM was precipitated by the addition of acetone at $-20^{\circ} \mathrm{C}$, collected by centrifugation, dissolved in saline, dialysed against distilled water in benzoylated dialysis tubing with a mol.-wt cut-off of $2 \mathrm{kDa}$, and then lyophilised. This crude material was used in the subsequent studies. Every attempt was 
made to ensure that endotoxin contamination during extraction was kept to a minimum. The protein content of the precipitated SAM was determined by the method of Lowry ${ }^{3}$ with bovine serum albumin as a standard and the carbohydrate content was assessed by the method of Dubois et $a l .^{4}$ with glucose as standard. The endotoxin content was determined by the chromogenic Limulus amoebocyte lysate assay (Pyrogent, Byk-Mallinckrodt) used according to the manufacturer's instructions. To determine if the osteolytic activity of the SAM was proteinaceous, solutions containing SAM $2.0 \mathrm{mg} / \mathrm{ml}$ were heated to $80^{\circ} \mathrm{C}$ for $1 \mathrm{~h}$ in a water bath before testing in the bone resorption assay. SAM preparations at a concentration of $2.0 \mathrm{mg} / \mathrm{ml}$ were also incubated at $4^{\circ} \mathrm{C}$ for $18 \mathrm{~h}$ in the presence of trypsin (Sigma) $0.25 \%$. Soya bean trypsin inhibitor $0.75 \%$ was then added before dilution of the SAM and addition to the bone cultures. Controls consisted of cultures of murine calvaria stimulated with SAM incubated at $4^{\circ} \mathrm{C}$ for $18 \mathrm{~h}$ without trypsin and calvaria with the mixture of trypsin and trypsin inhibitor but without the SAM.

\section{Electronmicroscopy}

The efficacy of extraction and the subsequent integrity of the bacteria were examined by transmission electronmicroscopy as described previously. ${ }^{2}$ Briefly, a part of the bacterial suspension was fixed in glutaraldehyde $3 \%$ in $0 \cdot 1 \mathrm{~m}$ sodium cacodylate buffer for $1 \mathrm{~h}$ at room temperature. A second portion was fixed in the same manner except that the fixative also contained ruthenium red, $0 \cdot 15 \%$ an electron-dense stain, to demonstrate the surface-associated components. Bacteria were then pelleted by centrifugation at low speed, the fixative was decanted and the pellet was washed in cacodylate buffer. Control cells were then post-fixed in osmium tetroxide $1 \%$ in cacodylate buffer for $2 \mathrm{~h}$ at room temperature. Test cells were treated identically except that the post-fix also contained ruthenium red $0.15 \%$. The fixative was decanted after centrifugation, and the pellets were washed in cacodylate buffer, then dehydrated in a graded series of ethanol concentrations and embedded in Araldite. Sections were cut on a Reichert Ultracut E ultramicrotome with a diamond knife and examined (unstained) in a JEOL 100CXII electronmicroscope.

\section{SDS-PAGE of SAM}

The proteins present in the saline extracts of the two periodontopathogens were resolved by SDS-PAGE ${ }^{5}$ with a commercial Minigel apparatus (SE 250 Hoefer Scientific Instruments, San Francisco, CA, USA).

\section{Calvarial bone resorption assay}

Bone resorption was assayed by measuring the release of calcium from 5-day-old mouse calvaria (five per group) with $1.5 \mathrm{ml}$ of BGJ medium (Flow Labora- tories, Irvine) supplemented with complementinactivated rabbit serum (Gibco, Paisley) $5 \%$ and ascorbic acid (Sigma) $50 \mu \mathrm{g} / \mathrm{ml}^{6}{ }^{6}$ After $24 \mathrm{~h}$, the culture medium was removed and replaced with fresh medium containing various concentrations of SAM or SAM plus various inhibitors. In all assays, prostaglandin (PG) $\mathrm{E}_{2}$ was added to five of the wells at $10^{-6} \mathrm{M}$ as a positive control to show that the bone was responsive. The calvaria were cultured for a further $48 \mathrm{~h}$ and then the calcium content of the medium was measured by automated colorimetric analysis. ${ }^{7}$ In some experiments, the calvaria were freeze-thawed three times to kill the bone cells.

The statistical significance of the results was determined by use of the two-tailed Student's $t$ test. A $p$ value $<0.05$ was considered to be statistically significant.

\section{Osteoclast isolation and TRAP assay}

Wistar rats $(<24$ h old: Harlan Olac) were killed by cervical dislocation and the long bones were dissected, freed of adherent tissue, minced finely and agitated in a wide-bore pipette. The bone debris was allowed to settle and $100 \mu \mathrm{l}$ of cell suspension was removed carefully and added to individual wells in 96-well microtitration plates (Flow Laboratories). The plates were incubated for $30 \mathrm{~min}$, washed three times with Eagles' Minimal Medium (MEM) and SAM from $A$. actinomycetemcomitans was added at 10 -fold concentrations ranging from $10 \mathrm{ng} / \mathrm{ml}$ to $10 \mu \mathrm{g} / \mathrm{ml}$. The plates were incubated for $24 \mathrm{~h}$ at $37^{\circ} \mathrm{C}$ and tartrate resistant acid phosphatase (TRAP) was measured with a commercial assay kit (Sigma), as a marker of osteoclast activation/differentiation.

\section{Osteoclast differentiation assay}

BALB/c mice (6 weeks old: Harlan Olac) were killed by cervical dislocation; the long bones were removed, dissected free of adherent tissue, and split in two. The bone marrow was then removed and washed twice in MEM containing fetal calf serum (FCS) $10 \%$. The cell suspension was distributed into 24-well culture plates (Flow Laboratories) and incubated for 9 days in the presence of graded concentrations of SAM from $A$. actinomycetemcomitans ranging from $1 \mathrm{ng} / \mathrm{ml}$ to $10 \mu \mathrm{g} / \mathrm{ml}$. Fresh medium containing SAM was added every $48 \mathrm{~h}$ and, at the end of the incubation period, cells were fixed and cellular TRAP activity was demonstrated by a histochemical enzyme assay (Sigma). TRAP-positive cells containing more than three nuclei were counted as osteoclasts and in each experiment the total number of TRAP-positive cells/ well was counted blindly in four wells for each concentration of SAM.

\section{Inhibitor studies}

The possible contribution of LPS to the bone resorbing activity of the SAM was determined by 
adding polymyxin B (Sigma) $20 \mu \mathrm{g} / \mathrm{ml}$ to the SAM preparations or to A. actinomycetemcomitans LPS which were both added to calvarial cultures at a concentration of $1 \mu \mathrm{g} / \mathrm{ml}$. The role of prostanoids in bone resorption was tested by adding the cyclooxygenase inhibitor, indomethacin (Sigma) at $1 \mu \mathrm{M}$. The role of interleukin-1 (IL-1) was assessed by adding the IL-1 antagonist protein-IL-1 receptor antagonist (IL-1 ra : also known as IRAP Synergen, Boulder, CO, USA) ${ }^{8}$-at concentrations ranging from $100 \mathrm{ng} / \mathrm{ml}$ to $10 \mu \mathrm{g} / \mathrm{ml}$. The involvement of tumour necrosis factor (TNF) $\alpha$ in bone resorption was determined by adding the neutralising monoclonal antibody TN3-19.2 (produced by Professor R. Schreiber, Washington University School of Medicine and manufactured by Celltech Ltd, Slough). Concentrations of antibody added ranged from $0 \cdot 1$ to $10 \mu \mathrm{g} / \mathrm{ml}$. These inhibitors were added to calvarial cultures at the same time as the $\mathrm{SAM}$, which was used at a concentration of $1 \mu \mathrm{g} / \mathrm{ml}$ in all studies.

\section{Results}

\section{Electronmicroscopy}

The ruthenium red-staining extracellular layer that was present on both species was absent after saline extraction and the bacteria were intact with no signs of damage. Also, there was no evidence of fimbriae, pili or S-layers.

\section{Composition of SAM}

The protein and carbohydrate content of SAM from A. actinomycetemcomitans were $44 \%$ and $13 \% \mathrm{w} / \mathrm{w}$,

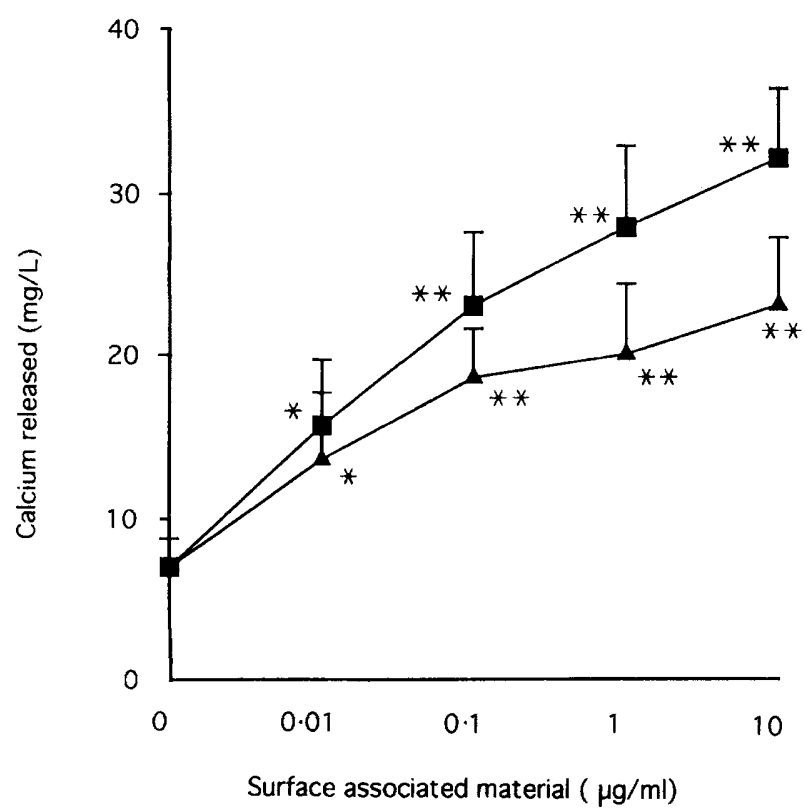

Fig. 1. The bone resorbing activity of SAM from A. actinomycetemcomitans $(\mathbf{A})$ and $E$. corrodens $(\boldsymbol{D})$ measured as calcium release in $\mathrm{mg} / \mathrm{L}$. The points represent the mean and SD of five cultures. $\left({ }^{*} p<0.05,{ }^{* *} p<0.001\right)$. Similar dose response graphs were obtained in four separate experiments. respectively, and for $E$. corrodens, $16 \%$ and $5 \%$. The endotoxin present in $1 \mathrm{mg} / \mathrm{ml}$ solutions of SAM from both bacteria was $1-10 \mathrm{ng} / \mathrm{mg}$, and SDS-PAGE analysis revealed proteins with mol. wts ranging from $>70 \mathrm{kDa}$ to $c$. $14 \mathrm{kDa}$. The distribution of bands suggested that SAM preparations from these species were different in composition.

\section{Bone resorbing activity of $S A M$}

SAM from both species stimulated reproducibly the release of calcium from cultured murine calvaria and the dose response in one representative assay is shown in fig. 1. The dose range was from $10 \mathrm{ng} / \mathrm{ml}$ to $10 \mu \mathrm{g} / \mathrm{ml}$ and the SAM preparations from both $A$. actinomycetemcomitans and $E$. corrodens consistently demonstrated statistically significant activity at the lowest concentration tested $(10 \mathrm{ng} / \mathrm{ml})$. In some experiments, both SAMs showed activity at $1 \mathrm{ng} / \mathrm{ml}$.

Additional evidence that the bone resorbing activity of the SAM was not due to LPS contamination was provided when polymyxin B was added to cultures. Polymyxin B binds to and inactivates LPS and this effect can be clearly seen in fig. 2 , when it was added to bone cultures exposed to LPS from A actinomycetemcomitans. In contrast, the same concentration of polymyxin $\mathbf{B}$ had no effect on the bone resorption induced by either SAM preparation. Polymyxin B had no effect by itself when added to bone.

The nature of the bone resorbing activity of SAM was investigated by either heating it to $80^{\circ} \mathrm{C}$ for $1 \mathrm{~h}$ or exposing it to trypsin. Both treatments caused $60 \%$ loss in the bone resorbing activity of SAM from both species (results not shown).

\section{Effect of inhibitors}

The addition of $1 \mu \mathrm{M}$ indomethacin to calvarial cultures stimulated with SAM from E. corrodens consistently inhibited calcium release by $20-25 \%$. In contrast, indomethacin did not significantly inhibit bone resorption induced by SAM from A. actinomycetemcomitans (fig. 3).

The biological actions of IL-1 can be antagonised by IL-1 ra and the addition of this natural antagonist protein to unstimulated calvaria in culture had no effect on basal calcium release. In three separate experiments, inhibition of bone resorption by SAM from both organisms was observed only at IL-1ra $10 \mu \mathrm{g} / \mathrm{ml}$ and at this concentration the maximum inhibition of calcium release was only $25 \%$ (fig. 4).

$\mathrm{TNF} \alpha$ is another potent stimulator of bone resorption and to determine the role of this cytokine in SAM-induced bone resorption, a neutralising antibody to murine TNF $\alpha$ (TN3-19.12) was employed. The addition of this antibody to unstimulated calvaria had no effect on basal calcium release, but in three separate experiments, the addition of TN3-19.12 to calvarial cultures stimulated by SAM from E. corrodens produced almost complete inhibition of bone res- 


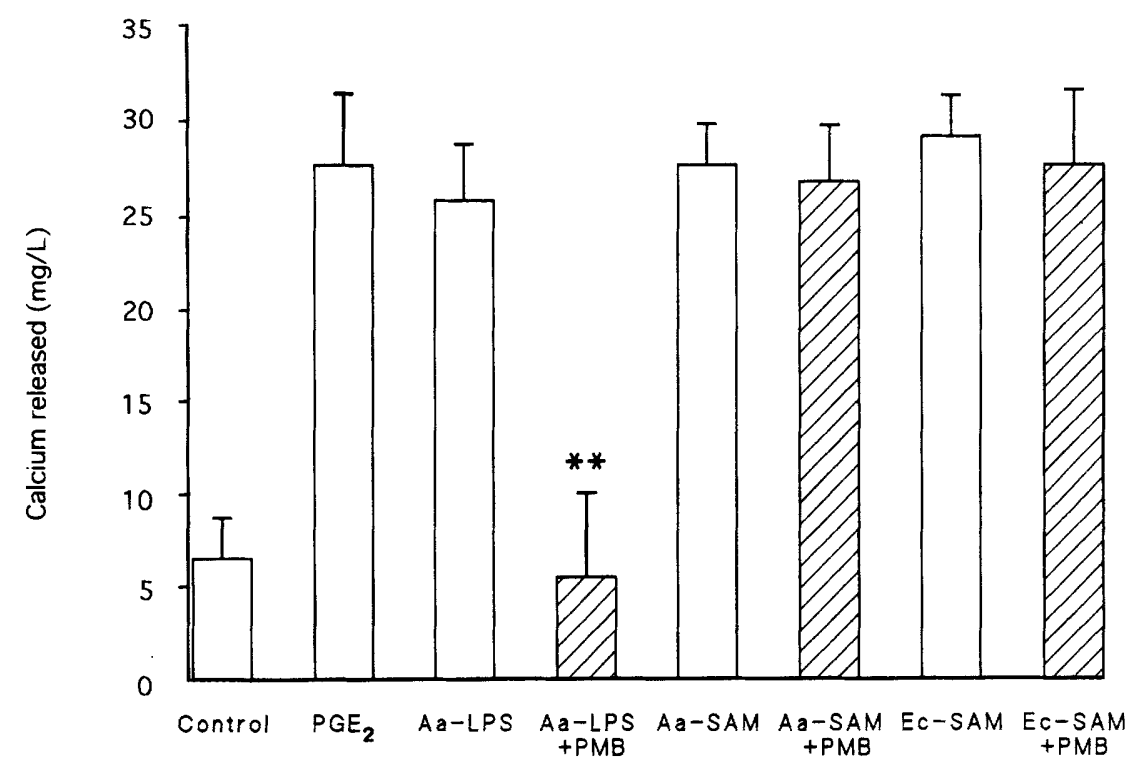

Fig. 2. The effect of adding polymyxin B (PMB) to calvarial cultures stimulated by lipopolysaccharide (LPS) from A. actinomycetemcomitans (Aa-LPS) or by SAM extracted from A. actinomycetemcomitans (Aa-SAM) or E. corrodens (Ec-SAM). The control culture shows the release of calcium from calvaria in the absence of any stimulus. The positive control $\left(\mathrm{PGE}_{2}\right)$ was stimulated with $1 \mu \mathrm{M} \mathrm{PGE}_{2}$. Each bar represents the mean and SD of five replicate cultures. PMB significantly inhibited calcium release by Aa-LPS $\left({ }^{* *} \mathrm{p}<0.001\right)$ but had no effect on that stimulated by the SAM preparations.



Fig. 3. The inhibition of bone resorption induced by SAM from A. actinomycetemcomitans (Aa) or E. corrodens (Ec) in the absence or presence of $10^{-6} \mathrm{M}$ indomethacin (Indo). The control represents the release of calcium in unstimulated cultures and $\mathrm{PGE}_{2}$ is the positive control $(1 \mu \mathrm{M}$ $\mathrm{PGE}_{2}$ ). Each bar represents the mean and SD of five cultures. Indomethacin significantly inhibited the bone resorption induced by SAM from E. corrodens $\left({ }^{*} \mathrm{p}<0.05\right)$ but did not significantly inhibit bone resorption caused by SAM from A. actinomycetemcomitans.

orption (fig. 5). In contrast, the antibody had no effect on the bone resorption induced by SAM from $A$. actinomycetemcomitans.

\section{Action of SAM from A. actinomycetemcomitans on freeze-thawed calvaria}

Calvaria were freeze-thawed to kill the bone cells and exposed to various concentrations of SAM from A. actinomycetemcomitans to determine if this material had caused calcium release by a direct proteolytic action. Over $48 \mathrm{~h}$, calcium release was similar when SAM was present or absent in the assay (results not shown).

\section{Action of SAM from A. actinomycetemcomitans on isolated osteoclasts}

Rat osteoclasts were exposed for $24 \mathrm{~h}$ to SAM over the dose range $10 \mathrm{ng} / \mathrm{ml}-10 \mu \mathrm{g} / \mathrm{ml}$. Even at the highest 


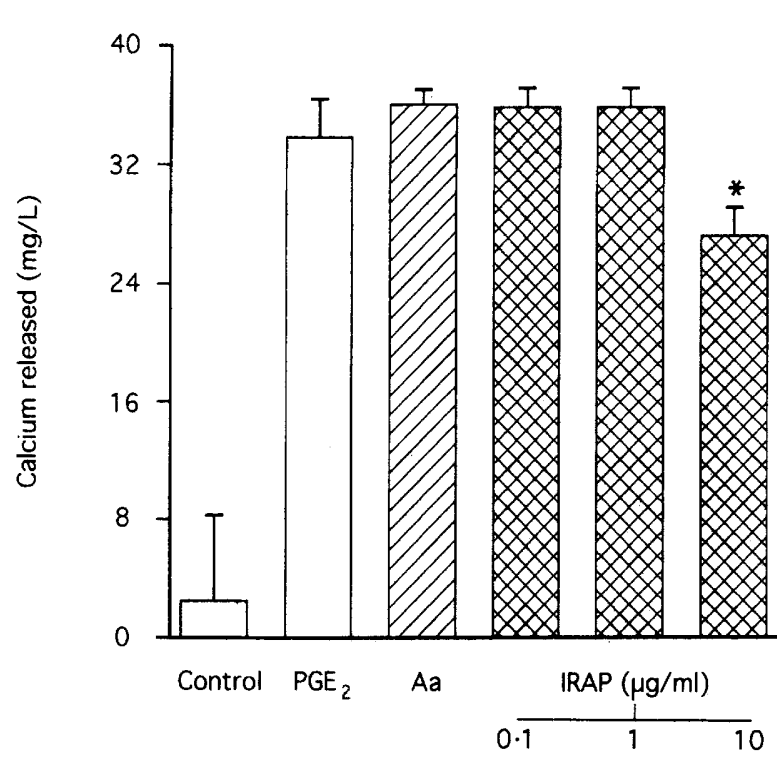

Fig. 4. The effect of IL-1ra (IRAP) on the release of calcium from murine calvaria stimulated by the addition of SAM $1 \mu \mathrm{g} / \mathrm{ml} \mathrm{w} / \mathrm{v}$ from A. actinomycetemcomitans. The control and PGE bars are as for fig. 3. Results are expressed as the mean and SD of five replicate cultures and experiments were repeated three times with consistent results $\left({ }^{*} p<0.05\right)$.

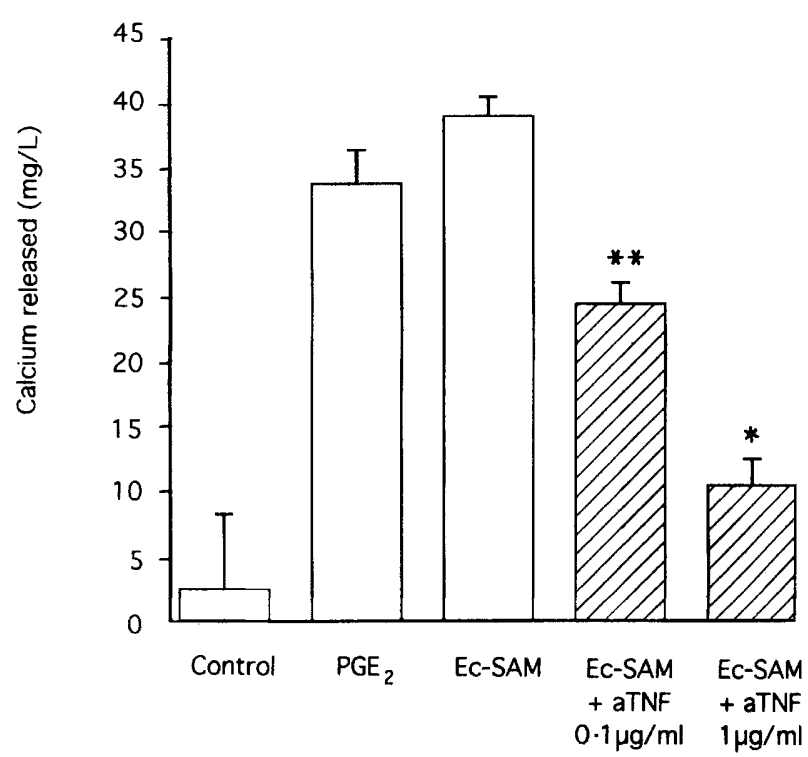

Fig. 5. The neutralising anti-TNF antibody TN3-19.12 (aTNF) in the calvarial bone resorption assay. Antibody was added at 0.1 or $1 \mu \mathrm{g} / \mathrm{ml}$ to cultures stimulated with SAM from E. corrodens (EcSAM). The control represents the calcium released by unstimulated cultures and the positive control cultures were stimulated with $1 \mu \mathrm{M}$ $\mathrm{PGE}_{2}$. Results are expressed as the mean and SD of five replicate cultures; anti-TNF antibody $0.1 \mu \mathrm{g} / \mathrm{ml}$ significantly inhibited $\left({ }^{*} p<0.001\right)$ calcium release induced by SAM from this organism.

concentration there was no significant increase in TRAP activity (results not shown).

\section{Action of SAM from A. actinomycetemcomitans on bone marrow multinucleate cell formation}

SAM was tested over the dose range from $1 \mathrm{ng} / \mathrm{ml}-$ $10 \mu \mathrm{g} / \mathrm{ml}$. There was no significant increase in multinucleate TRAP-positive cells in cultures exposed to 1 or $10 \mathrm{ng}$ of $\mathrm{SAM} / \mathrm{ml}$ but significant and dosedependent increase in TRAP-positive multinucleate

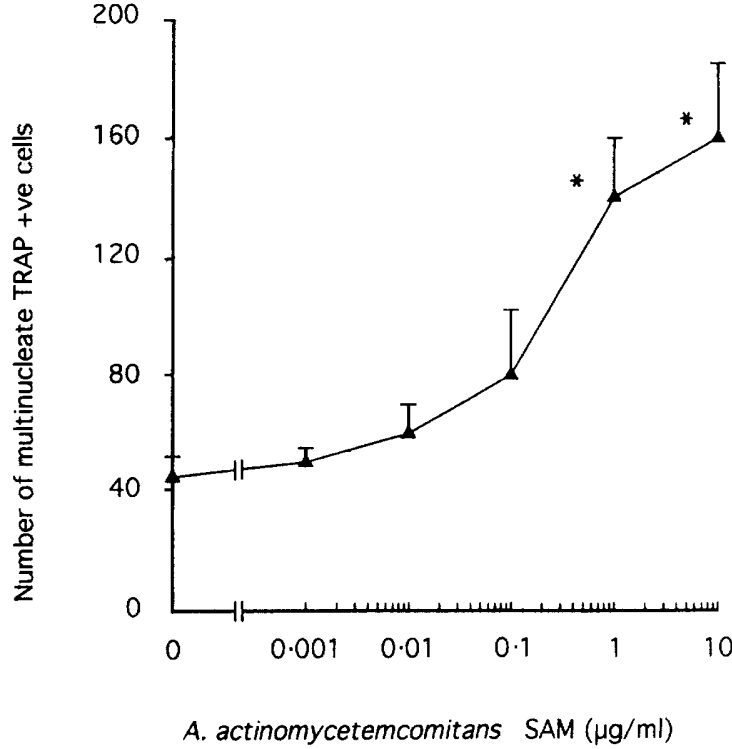

Fig. 6. Dose response graph showing the number of TRAP-positive multinucleate cells in the cultures of murine bone marrow after exposure to various concentrations of SAM from A. actinomycetemcomitans. Results are expressed as the mean and SD of quadruplicate cultures. $\left({ }^{*} \mathrm{p}<0.05\right)$.

cells was present at concentrations from $100 \mathrm{ng} / \mathrm{ml}-$ $10 \mu \mathrm{g} / \mathrm{ml}$ (fig. 6).

\section{Discussion}

The bone destruction and inflammation characteristic of chronic periodontitis is associated, in an as yet ill-defined manner, with subgingival plaque bacteria and their products. Disease symptoms may be due to the direct action of bacterial products or they may result from the stimulation of host mechanisms by these bacterial products. ${ }^{9}$ In the context of bone destruction, bacterial substances may activate osteoblasts or osteoclasts directly or they activate these cells indirectly by stimulating the synthesis of osteolytic mediators such as prostanoids or cytokines. The latter may require other cell populations (bone fibroblasts, leucocytes, etc.) to synthesise these mediators (i.e., paracrine stimulation) or it may work via an autocrine route in which the cell responding to these osteolytic mediators is also the cell synthesising the mediators. However, a prerequisite for bone destruction is that the bacterial components actually reach the target cells. In this respect, biologically active soluble surface components, especially those that could be shed during the growth of the organism, surface-associated proteins capsular material, S-layers, slime and fibrils, ${ }^{10}$ clearly have a greater "bio-availability" than less soluble components that are an integral part of the cell, e.g., LPS. The latter forms an integral part of the outer membrane of the gram-negative cell wall although it may be shed during growth and has low solubility in a physiological milieu.

Saline extraction and acetone precipitation allowed the recovery of a complex mixture of proteins and carbohydrates but left the bacteria intact. ${ }^{11}$ The 
majority of the material isolated was protein with a protein to carbohydrate ratio of between $2: 1$ and $3: 1$. SDS-PAGE analysis revealed a mixture of proteins in the mol. wt range of $c .14->70 \mathrm{kDa}$ and a different pattern of bands for each SAM.

In a previous study, ${ }^{2}$ SAM from $A$. actinomycetemcomitants proved to be a more potent stimulator of bone resorption than LPS. In comparison, the osteolytic activity of SAM from Porphyromonas gingivalis was far less potent, and was completely blocked by indomethacin, IL-1 ra or anti-TNF $\alpha{ }^{12}$ The results of this study demonstrated that SAM from $E$. corrodens also stimulates calvarial bone resorption and, on a dry weight basis, is as potent as that from $A$. actinomycetemcomitans. The nature of the active components is being investigated but since bone resorbing activity of the SAM from these three species is inhibited significantly by both heating or trypsin treatment, it is likely that protein is involved.

These findings demonstrate that the osteolytic activity of the SAM from $A$. actinomycetemcomitans is not a property unique to this organism but may be shared by a range of gram-negative periodontopathic bacteria. This strengthens the hypothesis that the readily solubilised surface constituents of bacteria within the periodontal pocket play a role in a alveolar bone destruction in patients with periodontal disease.

The Limulus assay demonstrated that the endotoxin contamination of the extracted SAM was between $1-10 \mathrm{ng} / \mathrm{mg}$. Even at the highest concentration of SAM used in these assays $(10 \mu \mathrm{g} / \mathrm{ml})$ this represents only $10 \mathrm{pg}$ of $\mathrm{LPS} / \mathrm{ml}$ in the calvarial media at which concentration, based on our previous studies ${ }^{2}$ the LPS is unlikely to have any effect. However, to rule out the possibility that the effects seen may be due to synergy between SAM and LPS polymyxin B, a cationic peptide which inactivates LPS, ${ }^{13}$ was added to cultures. The bone resorbing activity of LPS from $A$. actinomycetemcomitans was completely inhibited but the activity of the two SAM preparations was unaffected, strongly suggesting that the osteolytic activity was not due to contamination with LPS. This was further supported by the heat lability of the bone-resorbing components of the SAM preparations.

Bone resorption can be induced or stimulated by a number of pro-inflammaiory mediators and, in the context of periodontal disease, perhaps the most important are prostanoids such as $\mathrm{PGE}_{2}$ and the proinflammatory cytokines IL-1 and TNF $\alpha .{ }^{14}$ To determine the role played by prostanoids in SAMinduced bone destruction, indomethacin was added at a concentration that should completely block cyclooxygenase activity without producing the serious nonspecific effects that can be found with higher concentrations of this drug. ${ }^{15}$ Previously the addition of indomethacin has been shown to inhibit almost completely the bone resorption induced by LPS from $A$. actinomycetemcomitans at $1 \mu \mathrm{M}^{2}$ and SAM from $P$. gingivalis. ${ }^{12}$ In contrast, indomethacin had little effect on the bone resorption induced by the SAM from $A$. actinomycetemcomitans and had only a moderate effect (20-25\% inhibition) on the activity of SAM from $E$. corrodens.

IL-1 is probably the most potent activator of bone resorption, at least in vitro ${ }^{16}$ and, recently, a natural antagonist, IL-1 ra, has been cloned and expressed. ${ }^{17}$ This protein binds to the type I IL-1 receptor without triggering an agonist response and thus acts as a true receptor antagonist, blocking the biological activity of IL-1 both in vitro ${ }^{7}$ and in vivo. ${ }^{18,19}$ IL-1 ra can inhibit calvarial and long-bone resorption induced by human recombinant IL-1 in vitro. ${ }^{20}$ IL-1 ra had only a minimal effect on bone resorption induced by SAM from the two species tested here and only at high concentrations $(10 \mu \mathrm{g} / \mathrm{ml})$ which contrasts with its ability to inhibit the bone resorption induced by the SAM from $P$. gingivalis $(100 \mathrm{ng} / \mathrm{ml}) .^{12}$

TNF $\alpha$ is also capable of stimulating bone resorption $^{21}$ and if it was produced by the calvaria in response to SAM then the MAb TN3-19.12, ${ }^{22}$ which neutralises the biological activity of TNF $\alpha$, should inhibit bone resorption. At a concentration of $1 \mu \mathrm{g} / \mathrm{ml}$, this $\mathrm{MAb}$ inhibited the activity of SAM from $E$. corrodens by almost $80 \%$, which is similar to the result for SAM from $P$. gingivalis. ${ }^{12}$ In contrast, the activity of SAM from $A$. actinomycetemcomitans was not affected by neutralisation of TNF $\alpha$.

The mechanisms by which the three SAM preparations stimulate bone resorption are clearly very different. The osteolytic activity of SAM from $P$. gingivalis could be inhibited completely by blocking prostanoid synthesis or by neutralising the actions of IL-1 or TNF $\alpha$. The bone resorbing activity of the SAM from $E$. corrodens was slightly inhibited by indomethacin and almost completely inhibited by neutralising $T N F \alpha$. In contrast, the osteolytic effect of SAM from $A$. actinomycetemcomitans was unaffected by these various inhibitors. This suggests that the SAM from $P$. gingivalis caused bone resorption by stimulating bone cells to synthesise IL-1 and TNF $\alpha$, which then caused the synthesis of prostanoids. These various mediators presumably act synergically, which is why removal of any one of them inhibits bone resorption. The SAM from $E$. corrodens would appear to promote bone resorption largely by stimulating the synthesis of TNF $\alpha$, with the production of osteolytic prostanoids playing a minor role.

The mode of action of the SAM from $A$. actinomycetemcomitans is uncertain but does not appear to involve established osteolytic mediators. The activity of SAM from A. actinomycetemcomitans is not due to the presence of neutral endopeptidases capable of cleaving the conventional proteinase substrates-casein and gelatin (unpublished observations) - and it failed to release calcium from freeze-thawed calvaria where the bone cells have been killed, thus ruling out a direct effect on the matrix of the calvarial bone. Bone resorption is a complex event involving two main cell populations--osteoblasts and the osteoclasts--with the possible participation of other cells such as 
periosteal fibroblasts and osteocytes. Our initial assumption was that bacterial SAM stimulated cells in the calvaria to generate osteolytic signals (prostanoids and cytokines) which eventually led to the activation of the bone-resorbing osteoclasts. The finding that the SAM from A. actinomycetemcomitans was unaffected by any of the inhibitors and had no obvious proteolytic action suggested that it might directly influence osteoclasts. The possibility was addressed by adding SAM from A. actinomycetemcomitans to cultured rat long bone osteoclast cultures. No evidence was found for the activation of the osteoclast enzyme, tartrateresistant acid phosphatase (TRAP; a marker of osteoclast activation) suggesting that this material is not capable of directly interacting with osteoclasts to produce bone destruction. However, in the murine bone marrow assay, which is used commonly to test agents capable of stimulating the differentiation of osteoclast precursor cells, SAM from A. actinomycetemcomitans did stimulate TRAP-positive multinucleate cell formation, but the dose response was shifted to the right by one log dose compared to that in the murine calvarial bone resorption assay. Thus, it is still not established what osteolytic signals are stimulated by the SAM from A. actinomycetemcomitans and it is possible that it stimulates both osteoblasts and osteoclasts to promote bone resorption. Previously we have reported that the SAM from this organism possesses IL-1-like activities ${ }^{23}$ and we are currently fractionating the proteins present in this SAM to isolate this cytokine-like factor.

We thank the Wellcome Trust for financial support S. M. We also thank R. Thompson of Synergen for the gift of IL-1 ra; R. Schreiber, Washington University School of Medicine, St Louis, who produced the hamster antibody TN3-19.12; and Dr M. Bodmer, Celltech, who supplied the bulk-cultured antibody.

\section{References}

1. Daly CG, Seymour GJ, Kieser JB. Bacterial endotoxin: a role in chronic inflammatory periodontal disease? J Oral Pathol $1980 ; 9: 1-15$.

2. Wilson M, Kamin S, Harvey W. Bone resorbing activity of purified capsular material from Actinobacillus actinomycetemcomitans. J Periodont Res 1985; 20 : 484491.

3. Lowry $\mathrm{OH}$, Rosebrough NJ, Farr AL, Randall RJ. Protein measurement with the Folin phenol reagent. $J$ Biol Chem $1951 ; 193$ : 265-275.

4. Dubois M, Gilles KA, Hamilton JK, Rebers PA, Smith F. Colorimetric method for the determination of sugars and related substances. Anal Chem 1956; 28 : 350-356.

5. Laemmli UK. Cleavage of structural proteins during the assembly of the head of bacteriophage T4. Nature 1970 ; 227: $680-685$.

6. Zanelli JM, Lea DJ, Nisbet JA. A bioassay method in vitro for parathyroid hormone. $J$ Endocrinol $1969 ; 43: 33-46$.

7. Gitelman HJ. An improved automated procedure for the determination of calcium in biological specimens. Anal Biochem 1967; 18: 520-531.

8. Arend WP, Welgus HG, Thompson RC, Eisenberg SP. Biological properties of recombinant human monocyte-derived interleukin 1 receptor antagonist. J Clin Invest 1990; 85: 1694-1697.

9. Holt SC. Bacterial surface structures and their role in periodontal disease. In: Genco RJ, Mergenhagen S (eds) Host-parasite interactions in periodontal disease Washington DC, American Society for Microbiology. 182: 139.

10. Costerton JW, Irvin RT, Cheng K-J. The bacterial glycocalyx in nature and disease. Annu Rev Microbiol 1981; 35: 299-324.

11. Barber PM, Fletcher JM, Newman HN. Demonstration of the glycocalyces associated with three oral gram-negative bacterial species using a modern acrylic resin technique. $J$ Struct Biol 1993; 110: 180-187.

12. Wilson M, Meghji S, Barber P, Henderson B. Biological activities of surface-associated material from Porphyromonas gingivalis. FEMS Immunol Med Microbiol 1993; 6: $147-155$.
13. Vaara $\mathbf{M}$, Vaara $\mathbf{T}$, Jensen $\mathbf{M}$ et al. Characterization of the lipopolysaccharide from polymyxin-resistant pmrA mutants of Salmonella typhimurium. FEBS Lett 1981; 129 : 145-149.

14. Mundy GR. Inflammatory mediators and the destruction of bone. J Periodont Res 1991 ; 26 : 213-217.

15. Flower RJ. Drugs which inhibit prostaglandin biosynthesis. Pharmacol Rev 1974; 26: 33-67.

16. Gowen M, Mundy GR. Actions of recombinant interleukin 1, interleukin 2 and interferon gamma on bone resorption in vitro. J Immunol 1986; 136: 2478-2482.

17. Hannum $\mathrm{CH}$, Wilcox $\mathrm{CJ}$, Arend WP et al. Interleukin-1 receptor agonist activity of a human interleukin-1 inhibitor. Nature $1990 ; 343: 336-340$.

18. Cominelli F, Nast CC, Clark BD et al. Interleukin-1 (IL-1) gene expression, synthesis, and effect of specific IL-1 receptor blockade in rabbit immune complex colitis. $J$ Clin Invest 1990; 86: 972-980.

19. Henderson B, Thompson RC, Hardingham T, Lewthwaite J. Inhibition of interleukin-1-induced synovitis and articular cartilage proteoglycan loss in the rabbit knee by recombinant human interleukin-1 receptor antagonist. Cytokine $1991 ; 3: 246-249$.

20. Seckinger $\mathbf{P}$, Klein-Nulend J, Alander C, Thompson RC, Dayer J-M, Raisz LG. Natural and recombinant IL-1 receptor antagonists block the effects of IL-1 on bone resorption and prostaglandin production. J Immunol $1990 ; 145$ : 4181-4184.

21. Thomson BM, Mundy GR, Chambers TJ. Tumor necrosis factors alpha and beta induce osteoblastic cells to stimulate osteoclastic bone resorption. $J$ Immunol 1987; 138: 775-779.

22. Sheenan KCF, Ruddle NH, Schreiber RD. Generation and characterization of hamster monoclonal antibodies that neutralize murine tumor necrosis factors. I Immunol 1989; 142: $3884-3893$.

23. Harvey W, Kamin S, Meghji S, Wilson M. Interleukin-1-like activity in capsular material from Haemophilus actinomycetemcomitans. Immunology 1987; 60: 415-418. 